\title{
Full thickness rectal prolapse associated with primary intraabdominal pathology
}

\author{
Anjan K. Banerjee, B.T. Jackson and R.J. Nicholls
}

St. Thomas' Hospital, London SE1 7EH, UK.

\begin{abstract}
Summary: Full thickness rectal prolapse as a presenting feature of occult intraabdominal disease is rare. Two such cases are described and the possible mechanisms discussed. The importance of adequate investigation is emphasized.
\end{abstract}

Full thickness rectal prolapse occurs most often in elderly women and is usually unassociated with concurrent intraabdominal disease. Occasionally, prolapse secondary to symptomatic colonic or rectal pathology is observed but rectal prolapse as a presentation of occult intraabdominal disease is rare.

We present two patients with rectal prolapse concealing unrecognized intraabdominal disease.

\section{Case reports}

Case 1

An 80 year old woman presented with a 6 month history of full thickness rectal prolapse. She was faecally incontinent and had perianal pruritus, a mucous discharge and small amounts of rectal bleeding on defaecation. She complained of weight loss of about $12 \mathrm{~kg}$ over the preceding 4 months and a change in frequency of defaecation over the previous 2 months.

Physical examination was normal except for a palpable liver edge $1 \mathrm{~cm}$ below the costal margin and a $7.5 \mathrm{~cm}$ full thickness rectal prolapse. Digital rectal examination and sigmoidoscopy to $12 \mathrm{~cm}$ from the anal verge were normal.

Pre-operative investigations included normal blood indices, biochemistry and chest radiograph. A diagnosis of primary rectal prolapse was made and a Wells' Ivalon sponge rectopexy planned.

Laparotomy revealed a neoplastic mass in the rectosigmoid in continuity with a right-sided ovarian neoplasm $10 \mathrm{~cm}$ in diameter. The liver was normal. Anterior resection of the upper rectum and sigmoid colon, total hysterectomy and bilateral salpingooophorectomy were performed with a good recovery.

Correspondence: B.T. Jackson, M.S., F.R.C.S.

Accepted: 24 September 1985
Histology showed a primary ovarian cystadenocarcinoma with secondary spread to the colon.

\section{Case 2}

A 68 year old woman presented with a 2 month history of full thickness rectal prolapse and faecal incontinence. Three weeks before presentation she passed a small quantity of bright red blood during defaecation but there was no history of change in bowel habit. She reported intermittent lower abdominal pain and a loss of $4 \mathrm{~kg}$ in weight in over the previous two months.

Erythema ab igne was present over the lower part of the anterior abdominal wall but physical examination was otherwise normal except for a trace of bright red blood on the finger stall after digital rectal examination and the presence of a $7.5 \mathrm{~cm}$ full thickness rectal prolapse. Sigmoidoscopy to $13 \mathrm{~cm}$ from the anal verge was normal.

Pre-operative investigations included normal blood indices and biochemistry. The chest radiograph showed changes of old tuberculosis. A diagnosis of primary rectal prolapse was made and a Wells' Ivalon sponge rectopexy planned.

Laparotomy revealed a mass $8 \mathrm{~cm}$ in diameter in the mid-sigmoid colon with a fistula to an adherent loop of ileum. The fistula was divided, the ileum repaired and the sigmoid mass resected together with the upper rectum. The patient made a good recovery.

Histology showed sigmoid diverticulitis with no evidence of malignancy.

\section{Discussion}

Intestinal masses are recognized causes of full thickness rectal prolapse (Lamesch, 1983; Tovar, 1983). Several mechanisms have been postulated. First, the lesion itself may act as the apex of an intussusception (Goligher, 1984). In many instances, however, the 
associated pathology is distant from the intussusception. Secondly, the lesion may, by virtue of its size, exert a mass effect producing secondary rectal herniation. This hypothesis fits the theory that rectal prolapse is a variety of sliding hernia (Moschowitz, 1912). To exert any significant mass effect, however, the associated pathology would have to be of large size and this is by no means always the case. Thirdly, colonic pathology might produce partial intestinal obstruction causing constipation. Raised intraabdominal pressure caused by straining is a recognized cause of rectal prolapse (Nigro, 1978).

Sometimes the association of rectal prolapse and other disease is coincidental and it is possible that this was the case in our two patients. Dual pathology is often found in elderly patients and both diverticular disease and neoplasms are common in this age group.

Whatever the mechanism of the association, the possibility of associated intraabdominal pathology should be kept in mind in all patients presenting with a full thickness rectal prolapse. To what extent investigations should be carried out is debatable. Sigmoidoscopy should always be performed but it is often

\section{References}

GOLIGHER, J.C. (1984). In Surgery of the Anus, Rectum and Colon, 5th edition. Bailliere Tindall: London.

LAMESCH, A.J. (1983). An unusual hamartomatous malformation of the rectosigmoid presenting as an irreducible rectal prolapse. Diseases of the Colon and Rectum, 25, 452.

MOSCHOWITZ, A.V. (1912). The pathogenesis, anatomy and cure of prolapse of the rectum. Surgery, Gynecology and difficult to distend the rectum and obtain good views due to leakage of insufflated air past a patulous sphincter. A barium enema is often unsatisfactory for the same reason although this investigation, if successful, would have shown sigmoid disease in both our patients. In retrospect, the history of weight loss, change in bowel habit and abdominal pain perhaps should have alerted us to the possibility of colonic disease and the obtaining of contrast radiology, but to subject all patients with a rectal prolapse, many of whom are elderly and frail, to a routine barium enema is, in our view, undesirable.

It is clearly important to recognize underlying abdominal pathology as it will affect the management of the patient and the operation performed. In both our patients the underlying diagnosis was made at laparotomy and the planned operation changed but pre-operative diagnosis would have been preferable. The importance of a full examination of abdominal contents at laparotomy in cases of rectal prolapse is emphasized and is an argument for treating rectal prolapse by abdominal rectopexy rather than by a Thiersch wire or other anal encirclement procedures.

Obstetrics, 15, 7

NIGRO, N.D. (1978). Procidentia of the rectum. Surgicalo Clinics of North America, 58, 539.

TOVAR, J.A. (1983). Peutz-Jeghers syndrome in children:을 report of two cases and review of the literature. Journal of:Pediatric Surgery, 18, 1. 